\title{
Thomas Mann y las enfermedades infecciosas en la primera mitad del siglo XX. Parte II: Tuberculosis, cólera, trasplantes
}

\author{
Walter Ledermann ${ }^{1}$
}

\author{
Thomas Mann and the infectious diseases in the first half of 20th. century. \\ Second part: Tuberculosis, cholera and transplants
}

Surely Thomas Mann is today a forgotten writer, with only a little and selected group of readers between our young colleagues. However, perhaps could be useful for the others some knowledge about his vision of the infectious diseases in the first half of the twentieth century, when he wrote the novels here reviewed. Typhoid fever, meningitis, syphilis, tuberculosis and cholera are present in Mann's thematic from Buddenbrooks till Doktor Faustus, always with a personal focus, more on spirit - the will to live- rather than flesh and bones... or bacteria. One of his lasts and minor works let us throw an ironical glance over transplant, no so named, indeed, by Mann, who speaks of "exchange". In this second part we present tuberculosis, cholera and...transplant.

Keywords: Thomas Mann; Jules Verne; tuberculosis; cholera; transplant.

Palabras clave: Thomas Mann; Julio Verne; tuberculosis; cólera; trasplante.

\section{Propósito}

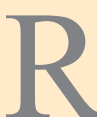
epitiendo lo que dijéramos en la Parte I y para quienes no han tenido ocasión de leerla, creemos no errar al considerar hoy en día a Thomas Mann como un escritor olvidado. Quizás algunos galenos en edad de retiro hayan leído en su juventud -antes de empezar a rellenar su intelecto de papers- La montaña mágica, su novela más relacionada con la medicina, pero con seguridad muy pocos, poquísimos, rara avis, nuestros colegas salidos de la universidad en el siglo XXI. Si los primeros podrán seguirnos en la revisión que aquí hacemos, a los últimos no les hará más daño que la lectura del Red Book.

Es muy poco lo que puede agregarse a los infinitos comentarios que señalan a Thomas Mann como escritor de excepción. Desdeñando por instinto los términos grandilocuentes y no pudiendo emplear con soltura los simples como él mismo lo recomienda, quedamos desarmados. Pero esto merece una explicación, que se encuentra en la cita siguiente: Precisamente por lo gastados que están los términos grandilocuentes, apenas sirven para nada cuando se trata de dar expresión a lo insólito, a lo extraordinario; esto se consigue en forma más satisfactoria recurriendo a las palabras modestas y sacándolas de su humildad, para elevarlas a la plenitud de su significado. Podemos, sin embargo, intentar destacar su real y sin igual mérito con las palabras de su hermano Heinrich "quien ha sido capaz de escribir Doctor Faustus", porque nunca, nunca, se podrá escribir mejor: ni siquiera él logró hacerlo, después.

\section{Tuberculosis}

En cuanto a esta patología, nos limitaremos sólo a un aspecto de las relaciones - puramente literarias- que el autor establece con la odiosa enfermedad a través del joven Castorp. Y este aspecto se centra en el bacilo de Koch de manera tal, que excluye cualquiera otra consideración.

Lo más llamativo, lo que asombra en esta Zauberberg $^{5}$ (Figura 1) que es el macizo del Berghof, es la -¿deliberada?- ignorancia que hace Mann del bacilo: ya habíamos reparado en los capítulos anteriores, al comentar la tifoidea y la meningitis, que el autor evitaba hablar de los gérmenes, enfatizando en cambio, y muy acertadamente, el rol etiológico del espíritu, de la voluntad y... del demonio. Este desdén por los seres pequeñitos se nos aparece ahora mayor que nunca.

En verdad, menciona a los bacilos, pero muy de pasada, al hablar del índice de Gaffky y presentarnos al doctor Behrens tiñendo láminas; incluso dedica una página o dos a los estreptococos. Sin embargo, al lado de los extensos párrafos dedicados al análisis de los estados de ánimo, que van decidiendo curso y pronóstico de la enfermedad toda, estas breves referencias al Mycobacterium aparecen como el supremo y desdeñoso desprecio hacia la cosa vil. Tratándose de células, un interés muchísimo mayor le merecen las del cuerpo humano, a las que dedica la mayor parte de un capítulo, donde llega a mencionar, como contrapunto, algunas algas del escalón biológico más bajo, pero no a las bacterias.

Empero, reconoce que, al fin y al cabo, los malvados bacilos ejercen alguna influencia sobre el estado general.
'Centro de Estudios Humanistas
Julio Prado.
Recibido: 24 de marzo de 2019

Correspondencia a: oncemayor@gmail.com 
Figura 1. Sanatorium Valbella, um $1915^{\circ}$ Dokumentationsbibliothek Davos

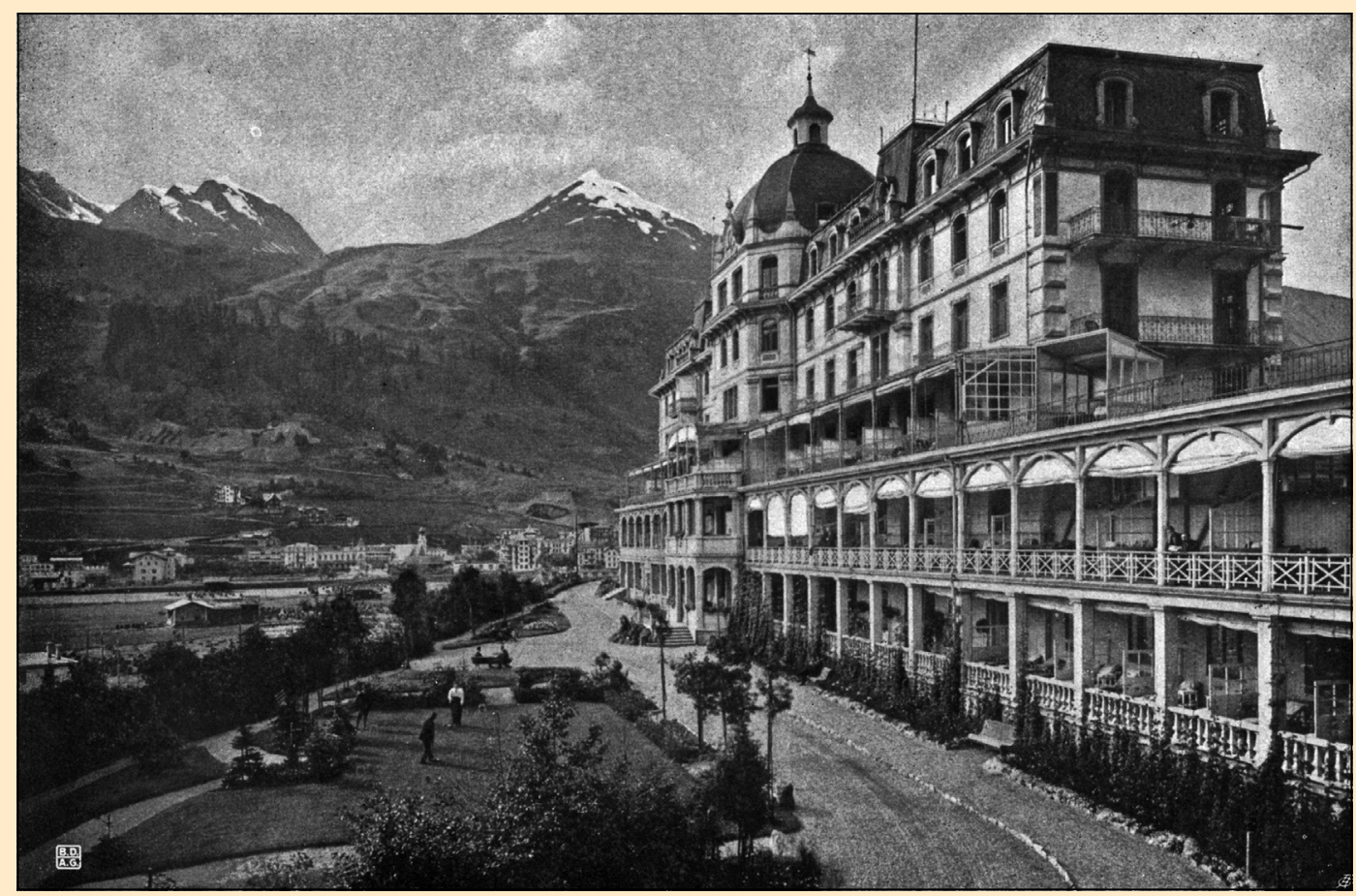

Lo hace de mala gana, con aquel sutil tonillo irónico que le es tan peculiar y que constituye su máximo encanto, al hablar, en dos o tres ocasiones, de las toxinas solubles de las bacterias, pero toda su concesión se reduce a reconocer su presencia en el lugar de los hechos al describir someramente un tubérculo. Pero luego - joh, sorpresa típicamente thomasiana! - desliza la hipótesis de si no sería, después de todo, la tuberculosis una enfermedad de la sangre. $\mathrm{Y}$ ya había dicho antes, por boca de un personaje ignaro, que era un mal hereditario, idea que aun hoy en día no se ha logrado desterrar de la pintoresca sabiduría popular.

Hay, también, algunas referencias a otros microbios: comentando los engaños a que puede conducir el solo análisis de la radiografía, el humanista Settembrini habla de una autopsia que demostró la muerte del paciente a causa de no sé qué microbios. "No sé qué microbios", "otros microbios"..."Otros"... ¿distintos de cuáles? ¿Si hay "otros”, cuáles son los "unos”? Jamás, jamás se decide Mann a escribir "el bacilo de Koch", aun siendo él también, como Robert, un alemán. ¿Por qué esa deliberada omisión en un escritor tan prolijo ? Porque de los estreptococos habla con todas sus letras, al mencionar Behrens que, curados los focos tuberculosos, la fiebre de Castorp pudiera deberse a la presencia de sus largas cadenas en la sangre.

Párrafo aparte merece, a propósito de estos estreptococos, la forma en que se realiza un hemocultivo, en placa de gelosa-sangre, donde el estreptococo viene a crecer recién después de una semana, formando colonias grises y punti- formes, a partir de las cuales se prepara una autovacuna, ya que en 1924 no había antibióticos, y con ella atormentan por semanas al protagonistas, con cero resultados. Esta autovacuna, relata el escritor, repugnaba a Hans Castorp, pues veía en ella una especie de incesto consigo mismo... ¡Siempre el rasgo original de "el Mago"!

Pero el análisis de las originalidades de Mann tornaría interminable este escrito: no olvidemos que la novela tiene 844 páginas en la edición gigante de Ercilla que hemos consultado. Sin embargo, algunas palabras debemos decir, antes de terminar, sobre la enfermedad misma.

Primero, Thomas Mann hace de la tuberculosis "la" enfermedad, la enfermedad con mayúsculas, genérica, universal. Como ocurre en todas sus obras con todos sus temas, la tuberculosis es un pretexto, un ejemplo para disertar sobre salud y enfermedad, dos estados espirituales, y así la enfermedad del jesuita Naphta, dice en alguna parte, heredada de su madre, brotó tanto por el clima nocivo como por sus esfuerzos intelectuales. Esta concepción de la enfermedad merece un estudio más amplio, que en esta ocasión preferimos evitar, para pasar a la patología pura y simple.

Segundo, en la descripción médica se advierte la preparación, la cuidadosa documentación previa del germano y vamos encontrando, en lenta sucesión, el rubor inexplicable y continuo de las mejillas, la disnea, los vértigos, la fiebre: Tenía la boca entreabierta, pues, a pesar de que no estaba resfriado, respiraba dificilmente por la nariz... Su corazón martilleaba a contratiempo 
de la música, lo que le producía una sensación penosa. Y la somnolencia había caldeado su rostro, a pesar que sentía intenso frio.

Tercero, en el examen físico el virtuosismo de que hace gala "el Mago" raya en la perfección. La percusión es auténtica, subyuga al lector profano y al experto suena a sinfonía. Golpea Behrens con la maestría de una larga práctica, y Krokovski, a cinco pasos de distancia, concentrado, la barba sobre el pecho, escucha el concierto, en medio de la silenciosa inquietud de los primos Ziemssen y Castorp. Es la atmósfera tan especial del consultorio, que sobrecoge y espanta al paciente hasta lo indecible cuando los hombres de blanco cruzan misteriosas frases que suenan a clave, sensación deprimente que se acentúa en la fantasmagórica sesión radiológica, donde los enfermos son sometidos a prolongadas radioscopias. ¿Sería costumbre de la época bombardear así a los tísicos ?

$\mathrm{Y}$, cuarto, sobre el tratamiento, tocante a drogas no hay nada, aparte de unas misteriosas e inútiles inyecciones, que durante un tiempo recibe Castorp dos veces por semana. Todo se centra en el aire de la montaña, que va a permitir la desintoxicación progresiva y que se acompaña de curas de reposo, de sol, paseos y otras terapias inofensivas. El neumotórax, que emergía entonces como la gran novedad, atrae la atención de Thomas Mann y le dedica sus páginas más pintorescas, que contrastan con la sobriedad de la novela. El formol se emplea a grandes dosis, para desinfectar las piezas de los fallecidos ${ }^{6,7}$. Y es todo: el autor prefiere omitir el resto y nosotros también.

Ignorado, el bacilo de Koch se retira de la mágica montaña terriblemente avergonzado, dejando el campo abandonado a las discusiones interminables entre el humanista y el jesuita.

\section{Cólera}

La muerte en Venecia ${ }^{8}$ fue publicada en 1912 y es una novela menor del gran maestro, en todo sentido, en temática, en tono y en extensión, aunque su llevada al cine le haya otorgado notoriedad. Está escrita como en voz baja, en sordina : el cólera aparece en un tono menor, como un asunto desagradable, del cual no puede hablar abiertamente la "gente bien". Todos los personajes secundarios lo mencionan como a pesar suyo, mirando a su rededor, temerosos de ser descubiertos en una infidencia. Desde luego, hay razones para esta actitud: reconocer la existencia de un brote de esa enfermedad temible espantaría a los turistas, la bella ciudad se vaciaría y las pérdidas para el comercio y la hotelería serían cuantiosas.

Recién en su cuarta semana en la ciudad, ya en la página 60 , el protagonista advierte algo raro: los turistas disminuyen, los alemanes se marchan, y el peluquero, hablando de una familia alemana que se marchó de prisa, le insinúa:
- Usted no se marchará, caballero; usted no tiene miedo al mal.

Cuando Aschenbach le pregunta a qué se refiere, el hombre enmudece, sintiendo que ha cometido una indiscreción imperdonable.

Ese mismo día siente el aire impregnado del olor dulzón de un desinfectante y ve fijar bandos en las paredes, en los cuales se advertía a la población que debia privarse de ostras y mariscos, así como del agua de los canales, a causa de ciertos desarreglos gástricos que el calor hacia muy frecuentes.

Aschenbach no se asusta ni reacciona, enamorado de un jovencito, al que contempla embelesado desde lejos: recordemos que, más que más temprano en la vida, "cambió de orientación sexual", como es hoy políticamente correcto decir. Y ya que hemos hablado de un peluquero, en sus Diarios anota cierto día que fue a cortarse el pelo con ese mozo buenmocito... Pero, volviendo al cólera, algunos días después, no sabemos cuántos, pues el autor nunca los cuenta, el protagonista interroga a un mozo a la hora del desayuno sobre el por qué de la continua desinfección de Venecia, y la respuesta es la misma del bando: es sólo una medida preventiva, a causa del calor, que acentúa los males gástricos. Ashenbach no se da por vencido y pregunta a un empleado inglés de una agencia de viajes, quien empieza con la explicación "oficial" pero, al advertir una mirada despectiva del alemán, por orgullo de raza, cuenta la verdad y traza la historia de la entrada del cólera indio en Europa y su dispersión por el continente, hasta llegar a la horrible situación actual: ... a mediados de mayo habían descubierto en Venecia, en un mismo día, los terribles síntomas del mal en los cadáveres ennegrecidos, descompuestos, de un marinero $y$ de una verdulera.

Aquí llegamos al punto más interesante para los infectólogos, al hablar de los síntomas y de las formas clínicas: Los casos de curación eran raros. De cien atacados, ochenta morían del modo más horrible; pues el mal aparecía con extraordinaria violencia, presentándose casi siempre en la más terrible de todas sus formas: la seca. El cuerpo no podía siquiera expulsar las grandes cantidades de agua que salian de los vasos sanguíneos. A las pocas horas, el enfermo moría ahogado por su propia sangre, convertida en una sustancia pastosa como pez, en medio de espantosas convulsiones y roncos lamentos. Podía considerarse feliz aquél en quien, como sucedia a veces, el ataque, después de un malestar ligero, se le producía en forma de un desmayo profundo del que ya nunca, o rara vez, despertaba.

¿De dónde sacó Thomas Mann esta forma seca? El cólera es, por naturaleza, húmedo: la toxina colérica produce una diarrea enorme, con veinte y cuarenta deposiciones diarias, tanto que en los lazaretos acostaban a los enfermos sobre una camilla de lona, con un agujero a la altura del 
ano y con un balde debajo... La diarrea, por cierto, no es un buen tema literario: en las novelas, los enfermos mueren limpiamente, de un ataque de "apoplejía", en medio de un delirio febril o de un desfallecimiento, y no hay fétidas deposiciones emporcando el ambiente dramático y romántico. Esta forma seca nos intrigó por años y revisamos todos los textos actuales, como el Red Book, el Manual Merck, el Feigin o el Gorbach, y en ninguno hablaba de ella, concordando todos en que por cada infección sintomática había cuatro o cinco asintomáticas, pero estos ni enfermaban ni fallecían, lo cual nos llevó a concluir que, o estaba Mann mal informado, o se había tomado la libertad de cambiar la enfermedad, para no tener que hablar de caca, hasta que dimos con un gran texto alemán de fines de siglo XIX, que el autor puede haber consultado, donde el Herr Profesor Eulenburg la menciona:

Con el nombre de cólera seco -dice Eulenburg- se han descrito observaciones, sobre todo en epidemias antiguas, en que la muerte sobreviene con rapidez, sin que durante la vida se haya observado diarrea alguna. Pero sin excepción se encontraba entonces en el intestino un contenido muy abundante, de modo que era muy probable que parálisis prematura de la musculatura intestinal hubiera impedido la evacuación ${ }^{9}$.

En este mismo volumen, sin duda presente en la biblioteca de muchos médicos alemanes cuando Mann escribía su novela, se aprecia claramente la confusión microbiológica de la época, pues en un mismo párrafo al Vibrio cholerae, ya descrito por Koch, se lo tilda sucesivamente de virus, bacteria y hongo (esquizomiceto $\mathrm{u}$ hongo hendido): Koch ha empezado a disipar la oscuridad que reinaba acerca de la naturaleza del virus colérico... debemos admitir con una probabilidad que casi constituye una seguridad completa, que el bacilo-coma es el hongo tan buscado del cólera...

Y así puede fallecer Aschenbach con elegancia y sin ensuciar los calzoncillos. Sentado, a la orilla del mar, baja la cabeza y muere; camino a la playa apenas había sentido vértigos, sólo a medias corporales, acompañados de cierto terror violento, de cierto sentimiento de encontrarse sin salida y sin esperanza, y que no sabía claramente si se referían al mundo exterior o a su propia existencia.

Decepcionante, infectológica y literariamente, esta muerte en Venecia.

\section{Los trasplantes}

Debemos confesar que, por un momento, pensamos titular este capítulo como "Julio Verne y la inmunología", disimulando así, aun cuando momentáneamente, el ligero rubor culpable que nos produce continuar fatigando la paciencia de los lectores con las novelas de Thomas Mann. Creíamos, y somos sinceros, haber puesto fin a este ensayo sobre la patología en la obra de "el Mago", pero he aquí que habíamos soslayado-involuntariamente, claro- los planteamientos que en Die vertauschten Köpfe, traducida en nuestra versión castellana como Las cabezas trocadas $^{10}$, hace sobre los trasplantes, tan equivocados como hoy en boga.

Por lo demás, pensamos que sin duda hemos incurrido en otras omisiones, pues no es imposible que en su temática múltiple haya Mann incursionado en otras parcelas médicas, y bastaría que apenas las hubiera rozado, para que la profundidad de su pensamiento las iluminara al punto de merecer nuestro modesto comentario. Y no es culpa nuestra tener que comentarlo, sino suya: entre los grandes escritores del siglo, supera a todos. Hesse es dolorosamente humano, Pirandello brillante y paradojal, France soberanamente virtuoso, Papini virulento y apasionado, y Kafka absurdo hasta su propia negación. Mann combina lo mejor de todos ellos y lo matiza con un tonillo especial, entre familiar e irónico, que constituye su personalísima gracia.

¿Y Julio Verne, por qué? ¿Acaso fue inmunólogo? No; lo curioso, lo verdaderamente extraño, es que este genial precursor en todos los campos de la ciencia no tuvo barruntos de la inmunidad. En el terreno biológico y médico, Verne dijo poco y, cuando dijo, desbarró. Revisemos brevemente su producción y encontraremos amnesia, psicosis y recuperación brusca ante un fuerte estímulo en La casa de vapor ${ }^{11}$ y Ante la bandera ${ }^{12}$; locura irreductible en dos capitanes de navío, el pobre Hatteras ${ }^{13}$ y el del Chancellor ${ }^{14}$; megalomanía en Robur y en variados maniáticos en todas sus obras, como Nemo, Maston, Strogoff, Karaban, Sandorff...Quizás si lo más original, médicamente hablando, de su obra está en sus entradas al campo de la oftalmología, al contarnos en Los hermanos Kip ${ }^{15}$ cómo una fotografía de la retina del muerto permite descubrir al asesino, y cómo, más fantástico todavía, las lágrimas que Strogoff dedica a su madre le salvan la córnea cuando el tártaro intenta cegarlo con un sable al rojo $^{16}$. Pero de inmunología, nada, de manera que Julio Verne, cuya imaginación parecía ilimitada, debe ceder también en su propia especialidad-la ciencia ficción-ante la maestría del escritor germano.

Las cabezas trocadas está considerada entre las obras menores de Thomas Mann, apenas un juego para distraerse entre concepciones mayores. Fue publicada en 1940, cuando todavía trabajaba en su monumental historia de José y sus hermanos, siete años antes que su genio culminara con Doctor Faustus. Era una época en que los trasplantes de órgano no pasaban de ser una amable fantasía médica, cuando el cirujano de Sudáfrica era aun incapaz de sonarse solo.

Más preocupado de las implicaciones morales de los trasplantes, el Mago soslaya con elegancia la parte técnica de la doble implantación, la gruesa y sangrienta cirugía, atribuyendo la proeza médica a la gracia divina, y al proce- 
der así se asemeja a todos los pacientes del mundo...Y que no anda muy descaminado en su apreciación lo prueba que los cirujanos suelen encomendarse a los poderes divinos antes de emprender tareas delicadas. La medicina mágica y totémica, no lo olvidemos, nunca será erradicada del temeroso corazón de los hombres.

¿Olvida el autor el problema del rechazo? Desde luego que no, pero lo evoca en forma simbólica. Y no podía ser de otra manera: el genio de Lübeck adora el gran simbolismo y no concibe los conflictos personales, unitarios, sino en la medida en que representan, traducen o interpretan un conflicto universal. El rechazo inmunitario no es para él la intervención vulgar de linfocitos y anticuerpos; el rechazo es espiritual, divino; el fatum castigará a los trasplantados; la necrosis, en la novela, es la necrosis de las almas.

Existen, claro, los cambios físicos, y Mann no los elude. Tan sólo rehúsa magnificarlos y los enumera de pasada, con cierta estudiada negligencia. El cuerpo de Nanda, el atlético pastor, sobre el que se implanta la cabeza del intelectual Brahmin Chirdaman, es modificado por ésta: hay atrofia muscular, caída del pelo y pérdida del color de la piel. Se nos dirá que estos trastornos tróficos no están descritos como secuelas de trasplantes, y responderemos que hasta ahora. ¿Además, acaso los corticoides, usados a amplia mano como inmunosupresores, no alteran al cabo la distribución de las grasas? Pues bien, en el cuerpo antes vigoroso y afinado del pastor aparece alguna grasa en el vientrecito. Y, atención, ved como describe la llamada "cara de luna" en la jerga médica, facie que tanto molesta a Jack London ${ }^{17}$ : los labios de su esposo, antes tan finos y delgados dentro de la barba, se hicieron más satisfechos y llenos, y hasta se volvieron hacia fuera, aproximándose a la hinchazón; cómo su nariz, un tiempo delgada como filo de cuchillo, aumentó en carnosidady hasta mostró una innegable inclinación a bajar y caer en lo caprino, y sus ojos adoptaron la expresión de una cierta alegría roma...

Pero dejemos estos insignificantes detalles clínicos, propios de un autor que siempre se documenta y que trabaja con cuidado sus obras, y lleguemos a la conclusión que de las implicaciones del trasplante deriva Mann. Ésta aparece por allí, disimulada entre los largos párrafos que suelta Chiridaman a los culpables Sita y Nanda: pero el amor pide la totalidad.

Pero el amor pide la totalidad, esto es, que aun cuando llegasen a solucionarse los fascinantes problemas de la autoinmunidad, de los fenómenos de rechazo y de todas las instancias en que bailan linfocitos y gammaglobulinas, jamás se alcanzará el éxito, porque el injerto habrá comprometido la totalidad. Así, la finalidad última del trasplante, que es salvar al individuo, estará falseada desde la partida y será apenas un miserable engaño clínico.

Aun cuando sea perfectamente inmune.

\section{Resumen}

Con seguridad Thomas Mann es hoy en día un escritor olvidado, para los infectólogos y para todo el mundo, con apenas un selecto grupo de poquísimos lectores entre nuestros jóvenes colegas. No les hará mal, a éstos y a aquéllos, sin embargo, adquirir algún conocimiento de las ideas sobre las enfermedades infecciosas en la primera mitad del siglo XX, período en que Mann escribió las obras aquí comentadas: por el contrario puede resultarles particularmente útil si este conocimiento les llega a través de la visión muy personal del germano, quien pone el foco más en el espíritu -la voluntad, el alma en suma- que en el componente físico de la enfermedad, en la miseria corporal, ignorando de paso, desdeñosamente, a las bacterias causantes.

\section{Referencias bibliográficas (Partes I y III)}

1.- Mann T. Buddenbrooks. Aguilar S.A., Madrid 1961.

2.- Mann T. Doctor Faustus. Editorial Sudamericana, Buenos Aires 1950.

3.- Hesse H. Rosshalde. Aguilar S.A., Madrid 1963.

4.- Valderrama A. Estudio sobre el período de invasión de las enfermedades. Anales Universidad de Chile 1863; XXII: 457.

5.- Mann T. La montaña mágica. Editorial Ercilla, Santiago 1950.

6.- Colbert C. Le traitement de la tuberculose pulmonaire en clientele. Maloine et fils, Paris 1923.

7.- Sergent E. Ribadeau-Dumas; Babonneix, L. Traité de Pathologie Médicale et de Therapeutique Appliqué. Vol X. La tuberculose. Maloine et fils, Paris 1920.

8.- Mann T. La muerte en Venecia. Editorial Planeta. Plaza \& Janés S.A. Barcelona 1977.

9.- Eulenburg A. Cólera. Diccionario Enciclopédico de Medicina y Cirugía prácticas. Traducido y arreglado para uso de los médicos españoles por el Dr. Isidoro de Miguel y Viguria. Agustín Jubera, editor, Madrid 1886: III: 10-8.

10.- Mann T. Las cabezas trocadas. Editorial Sudamericana, Buenos Aires 1944.

11.- Verne J. La casa de vapor. Editorial Molino, Buenos Aires 1961.

12.- Verne J. Ante la bandera. Editorial Molino, Buenos Aires 1961.

13.- Verne J. Aventuras del capitán Hatteras. Editorial Molino, Buenos Aires 1962.

14.- Verne J. El Chancellor. Editorial Molino, Buenos Aires, 1962.

15.- Verne J. Los hermanos Kip. Editorial Molino, Buenos Aires 1961.

16.- Verne J. Miguel Strogoff. Editorial Molino, Buenos Aires 1961.

17.- London J. El hombre cara de luna. Editorial Novarro, México 1967. 